\title{
Sobre vestes bárbaras, calças e tiaras: poder e alteridade na adoção de trajes estrangeiros por Alexandre Magno na Vida de Alexandre, de Plutarco
}

\author{
On barbaric dresses, trousers and tiaras: power and otherness \\ concerning the adoption of foreign dresses by Alexander the \\ Great in Plutarch's 'Life of Alexander'
}

\section{Thiago do Amaral Biazotto*}

Resumo: Tomando como fonte a Vida de Alexandre, do biógrafo e

Palavras-chave: Alexandre Magno; Trajes persas; Alteridade.

\section{Keywords:}

Alexander the Great; Persian dresses; Otherness.

\footnotetext{
* Doutorando em História da Arte pela Universidade Estadual de Campinas. Graduado em História e mestre em História Cultural, ambos pela Unicamp. Este artigo é derivado de minha dissertação de mestrado, que contou com apoio da Fapesp (Processo 2014/01462-0).
} 


\section{Introdução}

E ste artigo se debruça sobre a Vida de Alexandre, do biógrafo e historiador grego Plutarco de Queroneia (c. 45-120), buscando compreender as nuances de poder e alteridade dadas pelo autor às passagens em que o macedônio passa a adotar trajes persas. A partir do perscrutar das passagens pertinentes do texto plutarquiano, em cotejo à bibliografia auxiliar, será possível argumentar que Plutarco interpreta as vestes estrangeiras com duplo viés: em primeiro lugar, Alexandre lança mão delas de modo a melhor comandar seus conquistados - em um discurso de alteridade que reforça o caráter servil do outro; em segundo lugar, os paramentos persas são aquilatados por Plutarco como instrumentos de um exercício de poder autoritário e despótico, próprio do Grande Rei, aos quais o conquistador sucumbiu durante a campanha na Ásia. Além destes aspectos, também serão levados em conta o cenário em torno do qual Plutarco tomou a pena - durante o qual a ameaça parta fazia eco aos persas debelados por Alexandre - e a possível influência que Olímpia, mãe do conquistador, pode ter exercido na fascinação do basileu pelos adereços orientais.

Antes de passar à análise detida do objeto deste estudo, cabe expor duas preocupações nucleares: primeiro, apresentar dados elementares sobre a biografia de Plutarco, de maneira a sustentar as conclusões a que se chega a partir do exame da Vida de Alexandre; segundo, expor os fundamentos de conceitos como alteridade, poder e barbarização, que, em larga medida, norteiam este artigo.

\section{Trajetória de Plutarco e balizas teóricas}

Vindo de linhagem de sangue azul, Plutarco era neto de Lâmprias, filho de Autóbolos e irmão de Timon e Lâmprias, todos membros da nobreza beócia (SILVA, 2006, p. 25). Quando tinha por volta de vinte anos, Plutarco rumou para Atenas, imbuído do desejo de aprimorar seus saberes em filosofia, retórica, física e disciplinas correlatas, estabelecendo seus estudos sob a tutela de Amônio de Lâmprias. Seu mestre gozava de prestígio invejável, e liderava a academia platônica em Atenas quando da visita de Nero (37-68) à cidade, em 68. Após sua estada na Ática, o beócio escolheu viajar pelo mundo. Visitou Roma, Ásia Menor e Alexandria.

No começo da década de 70, sabe-se que Plutarco proferia lições filosóficas em Roma, quando se instruiu em latim e aprendeu pormenores da história local, que apareceriam em seus futuros textos. Sua boa relação com os romanos fez inclusive 
com que Trajano, já no século II, o investisse como procurador da Acaia, embaixador e prôconsul (MARTIN, 1969, p. 369).

Em dado momento, em meados da década de 90, Plutarco foi escolhido sacerdote de Apolo, no Santuário de Delfos, onde permaneceu por mais de 15 anos, provavelmente até sua morte - há uma inscrição que assevera que ele exerceu o sacerdócio até 117. Plutarco expirou, em Delfos, por volta de 120. A última notícia conhecida a seu respeito é a nomeação como procurador da Grécia, conferida por Adriano, em 119 (JONES, 1966, p. 63).

Em que momento da vida Plutarco começou a escrever permanece insondável, bem como a datação precisa de seus textos. O levantamento feito por Jones (1966) considera que a maior parte da produção plutarquiana é posterior ao ano de 96, após a morte de Domiciano e com o autor em idade avançada. A Vida de Alexandre, com efeito, não dispõe de datação precisa. Estima-se um ínterim de cerca de 30 anos, de 96 à morte do autor.

Se, por um lado, esta incerteza dificulta a análise minuciosa do contexto de sua publicação, por outro parece plausível admitir que, em especial durante os principados de Trajano e Adriano, sob os quais é possível que o texto de Plutarco sobre o macedônio tenha sido redigido, Alexandre gozava de certo prestígio nas lides imperiais, como bem exemplifica o afã de Trajano em comparar-se ao conquistador durante suas investidas contra os dácios e partas, aspecto que será debatido ao final deste texto.

Ademais, embora sucinto, este arrolamento permite notar que a trajetória pessoal e profissional de Plutarco sempre se encontrou nos limiares entre o centro do poder imperial e a ascendência, ainda que provincial, da literatura grega - não por acaso, o autor de Queroneia é um dos expoentes maiores da Segunda Sofística. Trafegando entre dois mundos, não seria surpreendente se o biógrafo usasse da Vida de Alexandre para aludir às aventuras imperiais romanas no Leste, como será aprofundado na sequência desta demonstração.

Com respeito às balizas temáticas e teóricas deste estudo, de pronto cabe explicitar o que se entende por barbarização de Alexandre. Trata-se da aquisição de costumes persas pelo conquistador, caracterizada, sobremodo para os fins do texto ora proposto, por seu desejo em implementar a prosternação e adotar parte da vestimenta dos Grandes Reis. Cabe pontuar que se adota uma definição abrangente de vestimenta, conforme proposta na obra Dress and Identity (1992), de Mary Ellen Roach-Higgins e Joanne B. Eicher, que inclui, além das peças da indumentária, mudanças na coloração da pele e do cabelo, bem como o uso de joias e acessórios diversos.

É também indispensável alertar que o termo barbarização é um neologismo, uma vez que não aparece na tradição escrita sobre o conquistador. Ao tratar dos incidentes 
em que Alexandre assume a conduta dos Grandes Reis, haverá sentenças como emulação

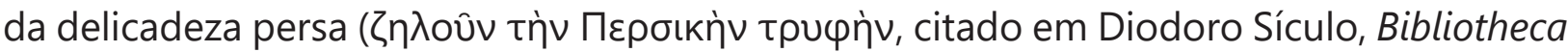

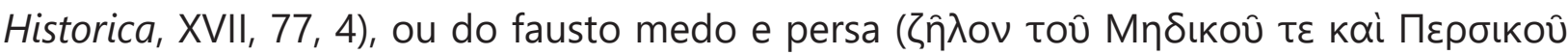
$\pi \lambda$ oútou, citado em Arriano, Anabasis, IV , 7, 4), ${ }^{1}$ mas não uma referência direta ao termo barbarização - o que não implica sua inexistência. ${ }^{2}$

Não obstante, seu emprego parece justificável à medida que condensa uma série de ações de Alexandre, que indicam sua filiação a certos protocolos da coroa persa. Também cumpre destacar que, embora do ponto de vista grego, bárbaro seja aquele que não partilha de seus costumes ou idioma, o persa, em especial após a vitória helênica na Batalha de Salamina (480 a.C.), representava uma espécie de bárbaro por excelência, o Outro que conjurava os medos mais soturnos (HALL, 1989; HALL, 1997; HARTOG, 1999; 2004; GARCÍA SÁNCHEZ, 2009 contra GRUEEN, 2011; VLASSOPOULOS, 2013). Nesta ordem de ideias, persianização e barbarização - embora ambos neologismos - podem ser expressões quase intercambiáveis.

Passando às questões de poder, o uso que se faz aqui da Vida de Alexandre é ciente da circulação, quiçá restrita, das obras escritas no seio da sociedade romana - cenário no qual o biógrafo empregou a pena, cabe reforçar - e do expressivo número de analfabetos no Mundo Antigo (STARR, 1987, p. 213-5). Por outro lado, por mais que o público alvo da literatura antiga fosse amiúde abastado, as mesmas obras registradas em suporte escrito eram declamadas em público (STARR, 1987, p. 223) - de resto, o próprio Plutarco tinha por hábito proferir palestras às mais abonadas cepas imperiais e, decerto, a relação entre elas e os tomos do autor de Queroneia era contígua (SILVA, 2008; STADTER, 2014).

Como propõem Alan Bowman e Greg Woolf (1998, p. 10), ademais, há dois aspectos fundamentais a se pensar quando se trata de cultura escrita: "o poder sobre os textos e o poder exercido por meio do uso desses textos". Enquanto o poder sobre o texto inclui restrições à escrita e ao tema, ao uso legítimo da palavra e às temáticas sobre as quais se escrevia, o poder exercido por meio dos textos se manifesta na "recriação literária do passado para justificar o presente" (BLOWMAN; WOOLF, 1998, p. 11-2), que se expressa pela retomada de certos assuntos em momentos específicos, além do papel da escrita sob a forma de leis, burocracia, contabilidade e controle da população (BLOWMAN; WOOLF, 1998, p. 13). De posse das preposições de Bowman e Woolf, fica claro como não somente escrita e poder caminhavam lado a lado na Antiguidade, como, sobretudo,

\footnotetext{
${ }^{1}$ Os textos antigos citados neste artigo foram extraídos, em seu original, do sítio Perseus, disponível em: <http://www. perseus.tufts.edu/hopper>. As traduções são de responsabilidade do autor.

2 Um possível exemplo aparece na Vida de Lisandro (III, 2), de Plutarco, quando o autor denuncia a estagnação econômica

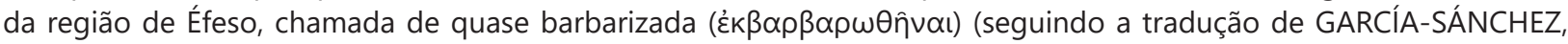
2007, p. 48, nota 108; cf. BRIANT, 2002, p. 701).
} 
Plutarco pode ter feito de sua Vida de Alexandre palco privilegiado para exprimir esta tensão permanente.

Por fim, no que concerne à alteridade, um dos caminhos possíveis é apresentar sua definição conforme delineada por Tzvetan Todorov, em A Conquista da América (2003). De acordo com Todorov (2003, p. 269), para "dar conta das diferenças existentes no real", isto é, no nível de percepção que ocorre quando grupos humanos antes separados se encontram, as sociedades e os indivíduos podem recorrer a um número definido de respostas e recursos retóricos. No entender do linguista búlgaro, três deles são os mais reconhecíveis, "nos quais pode ser situada a problemática da alteridade".

Das possíveis reações definidas por Todorov, a primeira seria o "julgamento de valor", responsável por taxar o Outro como "bom ou mau", "inferior ou superior" àquele que o julga. Em seguida, e como decorrência, haveria uma "ação de aproximação ou de distanciamento" em relação ao Outro, implicando a identificação ou alienação de seus valores. Na brecha entre estas duas, está a última réplica: o desejo de conhecer ou ignorar a "identidade do outro", a partir de uma "gradação infinita entre os estados de conhecimento inferiores e superiores" (TODOROV, 2003, p. 269-270).

Ainda que aplicado ao estudo da América, com suas peculiaridades, o raciocínio empregado por Todorov permite observar dois aspectos convenientes. $\mathrm{O}$ primeiro diz respeito a uma tarefa cara a cada pesquisa que se vale do conceito de alteridade; a necessidade de identificar as reações despertadas pelo encontro entre o eu - quer aquele que elabora as fontes, quer aquele que é narrado por elas - e o Outro, seja o do passado narrado, seja o do presente vivido pelos autores das fontes. No que concerne ao objeto desta pesquisa, será possível notar certo incômodo de Plutarco com a adoção dos hábitos do Grande Rei, por Alexandre. O persa, tido como o Outro pelo autor de Queroneia, aparecerá como portador de costumes degradantes, responsáveis pela queda do conquistador.

Entretanto, não basta apenas identificar reações de repulsa aos hábitos do Outro. Deter atenção aos possíveis matizes do fenômeno, observar as peculiaridades da fonte e perceber qual aspecto fustiga Plutarco com mais ardor são, da mesma forma, fundamentais. É neste ponto que a segunda lição de Todorov se fará sentir. Como afirma o linguista, há um leque de reações desencadeadas pelo encontro do Eu com o Outro. Da rejeição à absorção, do incômodo à indiferença, da repulsa à adoração - longe do binarismo simples -, observar cada resposta à assimilação do Outro por Alexandre será um dos fundamentos do artigo. O próprio Todorov (2003, p. 360) amarra o raciocínio em uma das mais belas passagens de $A$ Conquista da América: 
E, como a descoberta do outro tem vários graus, desde o outro como objeto, confundido com o mundo que o cerca, até o outro como sujeito, igual ao eu, mas diferente dele, com infinitas nuanças intermediárias, pode-se muito bem passar a vida toda sem nunca chegar à descoberta plena do outro - supondo-se que ela possa ser plena.

\section{A barbarização de Alexandre Magno segundo Plutarco}

\section{Quando trata do tema de interesse deste texto, Plutarco tem a bondade de precisar} o momento durante o qual Alexandre passou a fazer uso da vestimenta bárbara e de alguns protocolos da coroa persa: durante o outono de 330 a.C., enquanto se dirigia à Pártia, como mostra o trecho a seguir:

E, então, [Alexandre marchou] para a Pártia, onde, descansado e tendo tempo para o ócio, usou pela primeira vez a vestimenta dos bárbaros, quer ponderando acostumar-se às leis e aos costumes dos locais - ou acreditando que poderia com maior facilidade cativar seus habitantes - quer julgando introduzir a prosternação aos macedônios, acostumando-os pouco a pouco a tolerar as mudanças e alterações no seu modo de vida. [Todavia], não adotou [a vestimenta] dos medos, que era totalmente bárbara e de natureza alóctone, tampouco adotou as calças, nem o vestuário superior com mangas, nem a tiara, idealizando um modelo entremeado entre o dos persas e o dos medos, não tão soberbo quanto o dos últimos, mas mais majestoso do que o dos primeiros (Plutarco, Vita Alexandri, XLV, 1-2). ${ }^{3}$

As peças da indumentária persa nomeadas parecem ser um bom ponto de partida para a análise da passagem. Plutarco pontuará uma adoção parcial feita pelo conquistador, que teria recusado o uso das calças (áv $\alpha \xi u p i ́ \delta \alpha \varsigma)$, o vestuário superior

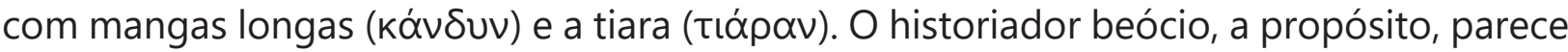

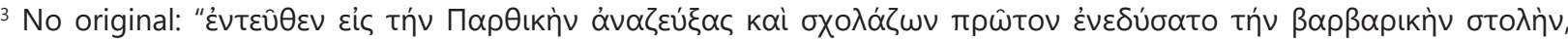

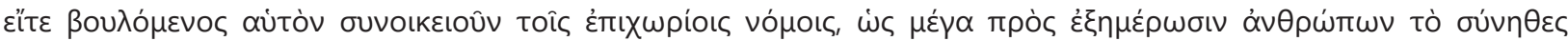

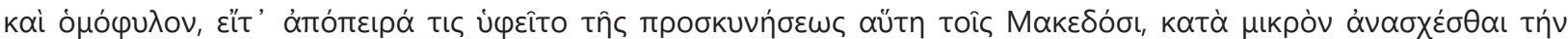

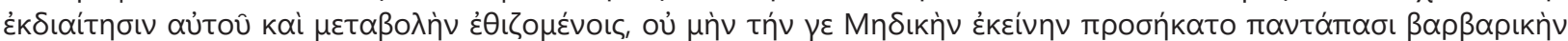

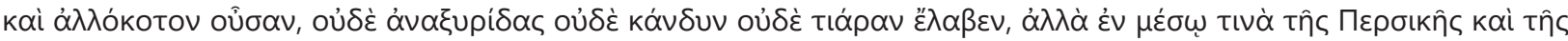

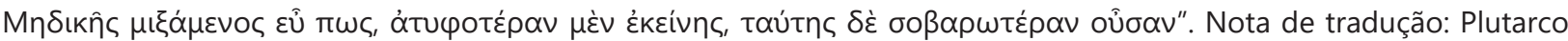

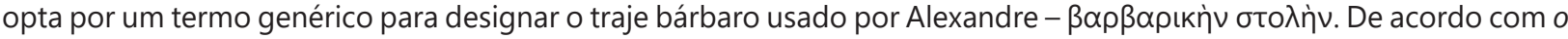
A Greek English Lexicon (1996, p. 1648), o termo otoגìv possui, em seu leque de conotações, a noção de equipamento, amiúde militar. Contudo, as edições modernas tendem a atribuir à expressão a conotação de indumentária, vide a inglesa ("barbaric dress") (Trad. Bernadotte Perrin), a francesa Belle Lettres ("l'habillement des Barbares") (Trad. Émile Chambry) e a espanhola Gredos ("vestidos bárbaros") (Trad. António Gúzman-Guerra). Isto somando à conotação em português que o termo estola possui - ("paramento sacerdotal que consiste em uma faixa larga de lã ou seda usada em torno do pescoço e que geralmente desce até os joelhos", segundo definição do Houaiss), faz com que a tradução optasse por vestimenta dos bárbaros. Curioso como no trecho seguinte, em que Plutarco poderia lançar mão de outro

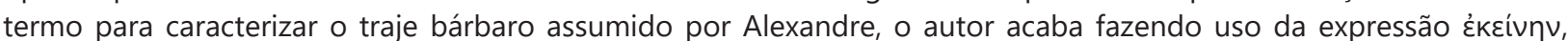
termo que, outra vez, segundo o A Greek English Lexicon (1996, p. 551), assume muitas vezes a conotação de pronome demonstrativo, como referência ao objeto citado imediatamente antes da expressão. Plutarco, assim, acaba deixando subentendido o termo, outra vez.
} 
mais interessado em discriminar as vestes estrangeiras recusadas pelo conquistador do que aquelas envergadas por ele. Sendo assim, Plutarco lança mão apenas do vago termo

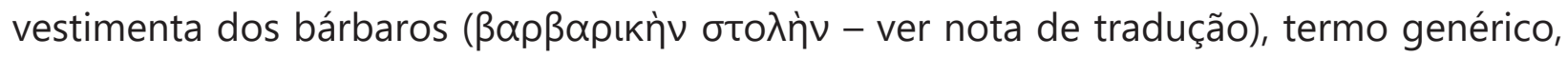
para caracterizá-la.

É preciso recorrer a outros autores para melhor caracterizar os trajes estrangeiros aos quais Alexandre renunciou. A tıápav, de partida, aparece referenciada em Heródoto (VII, 61), quando o historiador de Halicarnasso, ao descrever o exército de Xerxes, afirma que os persas cobriam suas cabeças com gorros flexíveis (i. e. de pano, de feltro), a que

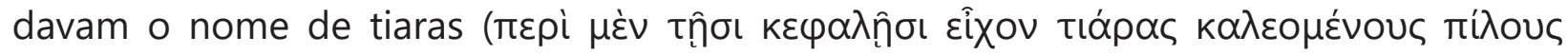

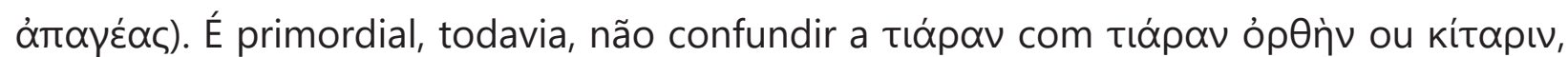
peças que, de acordo com a Ciropédia (VIII, 3, 13), de Xenofonte, eram de uso exclusivo do Grande Rei. O Greek-English Lexicon (1996, p. 997) atribui ao termo kítapıv o significado

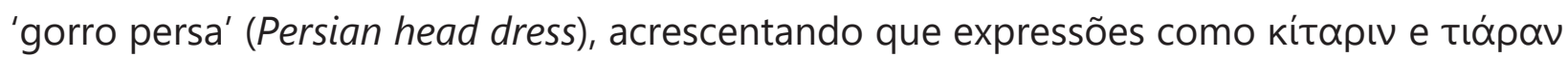

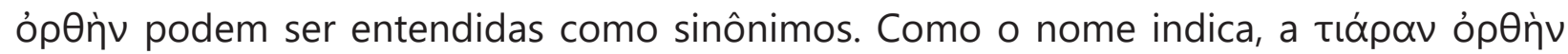
difere-se da tıópav por ser feita de pano mais resistente, deixando-a firme e reta, à diferença das peças usadas pelos persas comuns. Um exemplo iconográfico clássico para diferenciar as duas peças é o chamado Mosaico de Alexandre. Nele, Dario III aparece

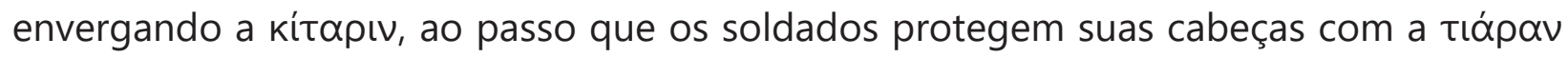
(GOLDMAN, 1993, p. 53; GARCÍA SÁNCHEZ; ALBALADEJO- VIVERO, 2014, p. 81).

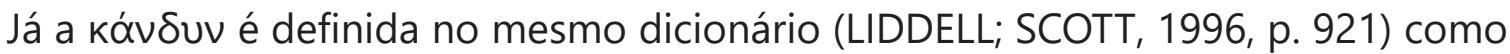
"median double" ou "upper garment with sleeves", traduzido aqui como vestuário superior com mangas, subentendido como persa pelo contexto do trecho. Contudo, a conotação de manto também faz jus à peça, como exemplifica a já citada passagem da Ciropédia (VIII, 3, 13). Ao descrever o vestuário de Ciro (c. 600-530 a.C.), o primeiro dos monarcas

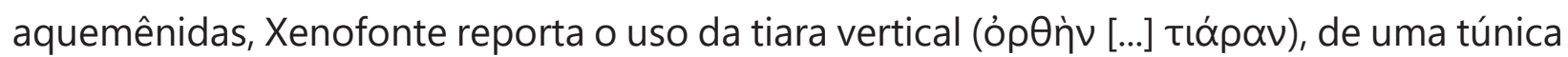

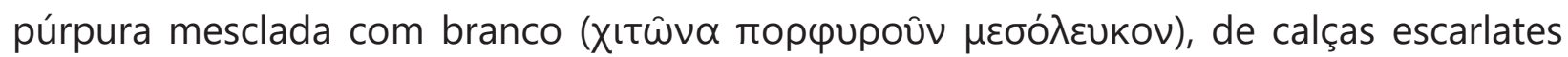

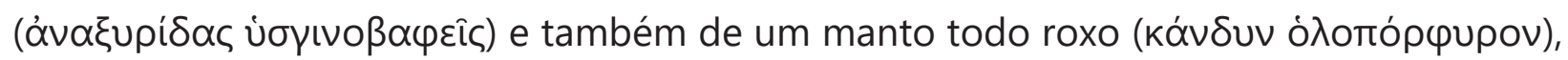

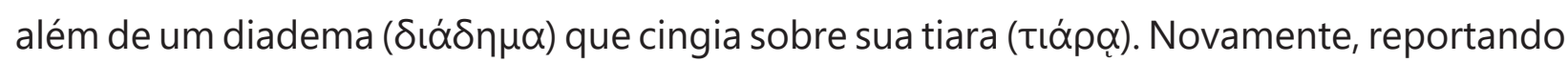
ao Mosaico de Alexandre, é possível divisar o uso de um manto roxo por Dario III, apesar do estado de conservação, ao passo que as calças estão em uso por todos os soldados persas da cena. A cobertura para as pernas, aliás, era um dos topoi da representação dos Aquemênida em vasos gregos, normalmente associada à fraqueza do persa, que luta com seu corpo todo coberto, em oposição à quase nudez dos helênicos (COHEN, 2012).

O autor de Queroneia também reserva comentários intrigantes sobre a motivação de Alexandre ao fazer uso da veste bárbara. De partida, tal adoção não era tributária da inclinação do macedônio ao fausto dos reis da Ásia ou à magnificência da monarquia persa, 


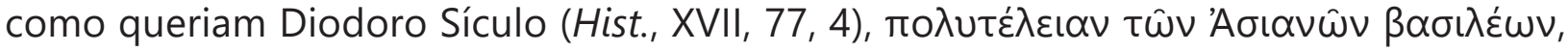
e Quinto Cúrcio (Historiae Alexandri Magni, VI, 6, 1) magnitudine [...] Persicae regiae, antecessores de Plutarco em narrar as proezas do conquistador. Segundo a Vida de Alexandre, o conquistador optou por envergar o traje estrangeiro com um duplo propósito: quer seja acostumar-se às tradições locais, quer seja cativar os habitantes dos territórios conquistados.

Ambas merecem comentário, sendo que a primeira parece revelar certo grau de consideração de Alexandre para com aqueles que venceu, a ponto de escolher paramentarse com suas próprias vestes. Esta hipótese, todavia, é minorada a partir da segunda consideração de Plutarco. Se, de fato, o rei macedônio passou a usar da vestimenta bárbara como ardil para cativar os locais, é possível vislumbrar um proeminente discurso de poder no raciocínio do beócio. A indumentária do bárbaro funciona mais como artifício para comandar os habitantes da Ásia do que como sinal de decadência do conquistador, como interpretam, em justa medida, Diodoro e Cúrcio.

A ideia de que a vestimenta estrangeira foi assumida por Alexandre de modo a cativar os locais também parece impregnada por latente narrativa de alteridade. Ao construir seu raciocínio, o autor de Queroneia parece caracterizar um Outro persa servil, tolo o suficiente para ser enganado mesmo pelos truques menos sofisticados de Alexandre. O bárbaro do discurso de alteridade de Plutarco é marcado como aquele que cai em todos os engodos. O traje bárbaro vergado por Alexandre torna-se, a um só tempo, dupla matéria de poder: por um lado, revela mais uma forma de exercício de comando utilizado pelo rei macedônio; por outro, expõe como o Outro é enganado por qualquer artimanha de controle, por qualquer instrumento de comando do basileu. Por fim, e a julgar pela inexistência de qualquer sublevação dos bárbaros nas páginas da Vida de Alexandre, Plutarco faz crer que o macedônio foi bem sucedido em seu subterfúgio.

Para continuar o exame, o contexto de produção de Plutarco ganha destaque. Ao externar uma das estratégias usadas por Alexandre na investida de comandar os bárbaros, seria possível que o beócio estivesse cristalizando um comentário ao cenário de expansão romana quando da possível redação da Vida de Alexandre? A possibilidade ganha fôlego ao se recordar que um dos possíveis imperadores contemporâneos à feitura do texto plutarquiano é Trajano, conhecido por suas expedições militares direcionadas ao Império Parta a partir de 113. Sendo assim, a opção do autor em mencionar o território dos partas (ПарӨเкท̀v) logo no início de seu excerto pode não ser fortuita.

Ademais, é fulcral notar que Plutarco não tem pudores em elucidar que a opção do macedônio em recusar certas peças do traje estrangeiro se baseava no caráter por demais

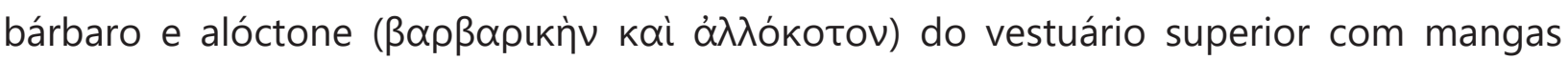


longas, das calças e da tiara, fazendo com que Alexandre criasse uma indumentária mista entre as peças medas e persas, menos luxuosa que a primeira, todavia mais majestosa que a segunda.

A primeira leitura do episódio é a de que Plutarco arriscou uma defesa de Alexandre, caracterizando-o como um rei preocupado com o fausto excessivo de seus trajes. Ao operar desta forma, Plutarco parece defender a estratégia do macedônio, em contraponto às demais fontes, que veem a adoção de trajes bárbaros como sinal de decadência de Alexandre. Este raciocínio faz com que Plutarco seja o único a mencionar o ardil da vestimenta mista levada a termo pelo macedônio.

Também é digno de nota que Plutarco promova uma cisão entre medos e persas, em especial no que concerne ao vestuário. Vale lembrar como um autor da envergadura de Estrabão, atuante cerca de um século antes de Plutarco, promove divisão semelhante. Em sua Geografia (XI, 13, 9), Estrabão sublinha que muitos dos hábitos persas derivavam dos medos, como a habilidade de cavalgar, atirar flechas e pegar tributos aos príncipes,

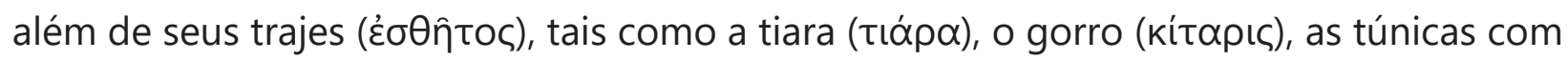

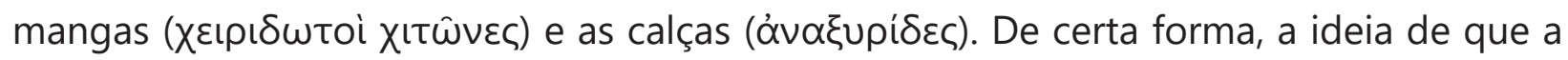
conduta faustosa dos persas é herança dos medos, é um dado que remonta ao menos a Heródoto, já que suas Histórias $(\mathrm{I}, 135)$ contêm interessante passagem a respeito da

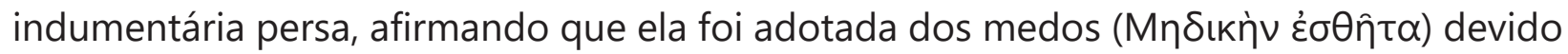
à sua beleza superior ( $\kappa \alpha \lambda \lambda i ́ \omega)$, aspecto que, em justa medida, também aparece sob a pena de Plutarco (BICHLER; ROLLINGER, 2002, p. 226-9).

Há ainda outros aspectos a se comentar, sendo o primeiro um discurso de alteridade bastante assertivo: a constatação de que Alexandre primeiro vestiu-se com a indumentária bárbara durante um momento de ócio. A retórica de diferença do autor de Queroneia parece reafirmar o topos do bárbaro preguiçoso e dado à indolência, à inação. O conquistador macedônio assume os trajes alóctones durante uma ocasião em que os combates haviam cessado, após sua decisiva vitória em Gaugamela (331 a.C.), quando Dario III, pela segunda vez, havia fugido do campo de batalha, ao divisar sua morte iminente. Como de praxe no discurso de alteridade, Plutarco parece sublinhar o paradoxo do Outro que, apesar de violento, sequer dispõe de trajes adequados ao campo de batalha. Ao contrário, todo seu indumento parece caracterizado pelo luxo desmedido. Desta forma, Plutarco acaba por corroborar a imagem do outro persa ocioso, que dispõe de tempo vago para adornar-se como trajes suntuosos.

Não é somente neste trecho, porém, que Plutarco faz menção à adoção do traje bárbaro por Alexandre. Na sequência de sua biografia do macedônio, o autor beócio faz publicar algumas das reações de seus companheiros às vestes orientais ora envergadas 
pelo basileu. Entre elas, ganha destaque a violenta altercação entre Alexandre e Clito, que será discutida na sequência.

\section{As reações dos macedônios à barbarização de Alexandre em Plutarco}

Como propôs Whitmarsh (2002, p. 182), o assassinato de Clito por Alexandre é o mais traumático evento envolvendo a barbarização do conquistador. Eis seu enredo: alguns emissários vindos da Grécia trouxeram frutas para Alexandre, que, maravilhado por sua beleza e frescor, mandou chamar Clito, para que o veterano as provasse. O general, contudo, estava procedendo a um sacrifício e, quando foi ao encontro do conquistador, três ovelhas consagradas seguiram-no. Sempre à procura de presságios, Alexandre consultou seus adivinhos, que consideraram a fuga um mau agouro. Três dias antes, o macedônio havia sonhado com o mesmo Clito; o veterano estava vestido de preto e cercado pelos filhos de Parmênio, que, àquela altura, estavam mortos, assim como o próprio general (Plut., Alex., L, 1).

Pouco tempo depois, membros da corte estavam envolvidos em uma bebedeira, quando cantos em zombaria aos macedônios começaram a ser entoados. Embora os convivas mais velhos se aborrecessem com aquilo, Alexandre não mandou cessar a canção, o que incomodou Clito. O conquistador fez pouco caso das queixas do veterano, o que o levou a lembrar-Ihe que Ihe havia salvado a vida durante a Batalha do Rio Grânico, sem que tivesse recebido as honras devidas (Plut., Alex., L, 5-6).

Alexandre contra-ataca dizendo que Clito apenas queria difamá-lo. O general, então, passa a fazer pesadas acusações contra a índole de seu antagonista: afirma que bem aventurados foram os macedônios que morreram antes de serem vergastados

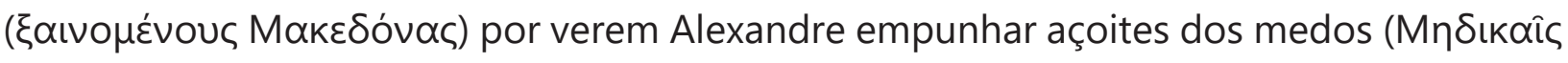

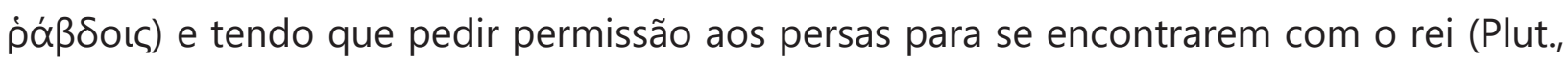
Alex., LI, 1). Ao notar que o basileu continuava a não cair em suas provocações, o veterano resolve ser ainda mais direto; intima o conquistador a viver apenas entre bárbaros e escravos

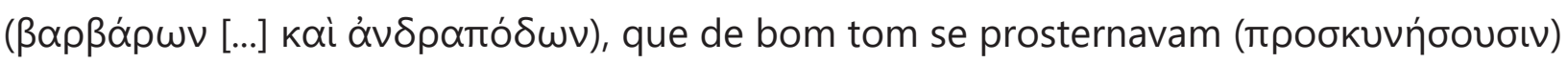

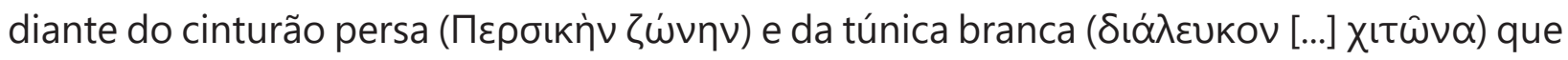
agora ostentava (Plut. Alex. LI, 3). Furioso, Alexandre atira uma maçã no general e parte em sua direção. É contido apenas pelo grande esforço da criadagem. Por fim, Clito recita o célebre verso da Andrômaca, de Eurípides (683): "Ai de mim! Que nefasto costume há

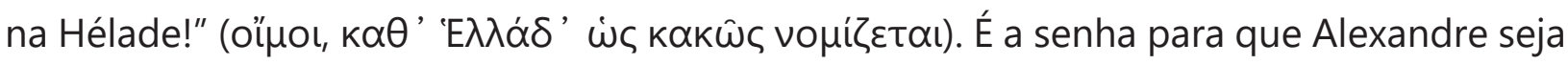
consumido pela cólera, atenuada apenas quando vê o corpo do rival caído, trespassado pelo golpe certeiro de sua lança. 
Sob diversos aspectos, a passagem acima é a que mais comove Plutarco em toda a Vida de Alexandre. À partida, deve-se notar o cenário em que a cena se passa, o banquete. A dar crédito à interpretação de Withmarsh (2002, p. 182), o festim possui incumbência específica na literatura plutarquiana: trata-se de espaço ambíguo, no qual os comensais devem, a um só tempo, tanto desfrutar de comida e bebida abundantes quanto mostrar capacidade de autocontrole, o que, de resto, encontra eco junto aos protocolos aristocráticos romanos vigentes à época de Plutarco (EDMUNDS, 1980). Desta forma, o primeiro erro de Alexandre é não ter conseguido controlar sua ira, sendo levado pelas afrontas de Clito.

Outro dado a se mencionar é que Plutarco adiciona novos itens ao inventário da barbarização do conquistador. O beócio refere-se a três itens do vestuário persa até então inéditos em seu texto. Clito lança acusações a Alexandre devido ao uso do cinturão persa

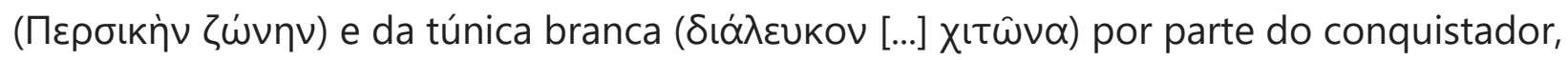

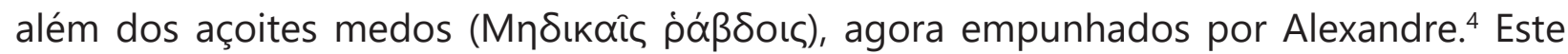
item, em particular, serve como mais um instrumento para a construção da retórica de alteridade de Plutarco, que será trabalhado na sequência do texto.

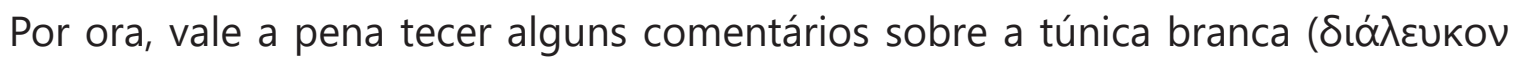

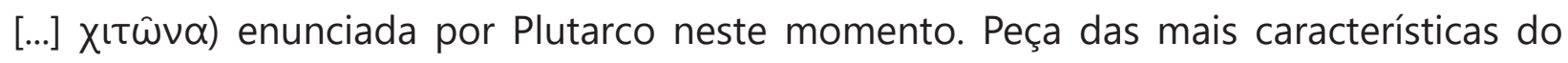
Grande Rei, o chíton aparece inclusive nas representações oficias da monarquia persa, como o famoso relevo de Persépolis, em que uma comitiva apresenta-se diante de Dario I (550-486 a.C.) trazendo-Ihe tributos e saudando-o com o obséquio (ROAF, 1983, p. 115). Também os autores greco-latinos não se furtaram a comentá-lo, como foi possível notar a partir da referência de Xenofonte à túnica púrpura mesclada com branco ( $\chi \imath \imath \hat{\omega} v \alpha$

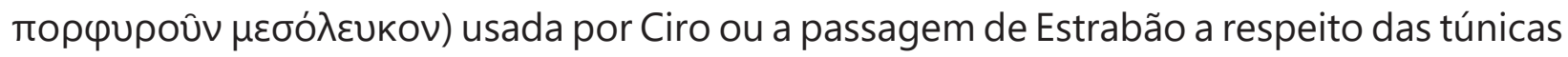

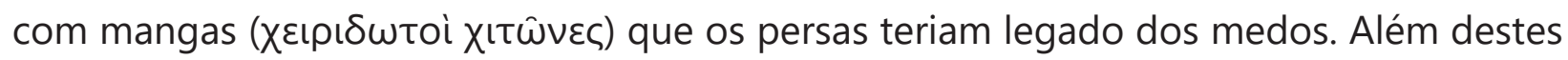
dois exemplos, Quinto Cúrcio (Hist., III, 3, 17) relembra que Dario III usava uma túnica púrpura dividida por uma franja branca (purpureae tunicae medium album intextum erat), além de o próprio Grande Rei, representado no Mosaico de Alexandre, paramentar-se com um chíton de cor alva. Plutarco, portanto, faz coro a uma longa tradição de retratar o soberano persa vestido com uma túnica branca.

Já o incômodo externado por Clito, ao ver Alexandre empunhar o açoite dos medos, parece motivado pela intenção de Plutarco em transformá-lo em um signo de submissão, artefato que representa o ápice da tirania. Materialização da condição sobre-humana e

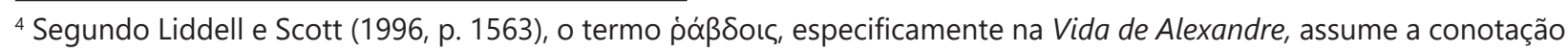
de vara de castigo (rod for chastisment). Para preservar o sentido da expressão, a tradução optou por açoite. 
semidivina da qual goza o Grande Rei. Plutarco reforça o jargão do Outro que não tem governantes, mas tiranos, que não tem companheiros, mas escravos, e nada melhor que o açoite medo, por ora nas mãos de Alexandre, para caracterizar os fundamentos da monarquia oriental. A própria gravidade da reação de Clito diante do uso - simbólico ou não - do açoite mostra o quão aviltado ficou o biógrafo de Queroneia diante da nova atitude do conquistador. Afinal, como fazem lembrar García Sánchez e Albaladejo Vivero (2014, p. 79-80), os pavilhões reais, como o trono, o cetro, o manto e coroa, têm tanto poder simbólico quanto o próprio monarca

É também imperativo notar como Plutarco novamente associa a adoção de trajes e artefatos estrangeiros a questões de poder. Se no primeiro trecho comentado o autor

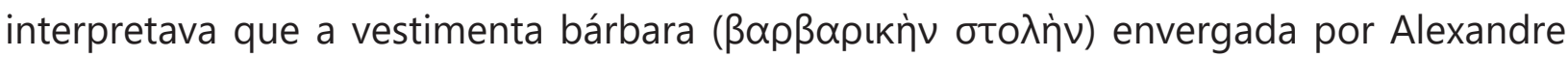
representava um ardil do conquistador para cativar os habitantes locais - e, portanto, minar sua resistência e poder frente à investida do basileu -, agora o açoite dos medos aparece mencionado por Clito como metonímia dos modos de exercício de poder do Outro. A violência, a submissão e a agressividade ganham corpo no artefato e nas atitudes nefastas de Alexandre ao empunhá-lo: a bebedeira excessiva que leva à morte de um de seus companheiros mais próximos.

Por fim, vale destacar como, no trecho analisado, Plutarco menciona outras duas peças da indumentária aquemênida inauditas na Vida de Alexandre: o cinturão persa

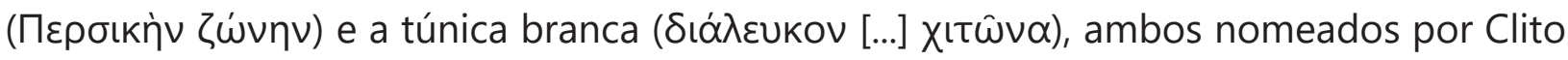

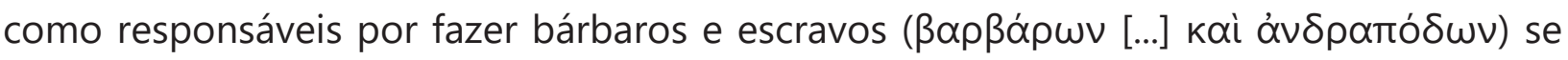

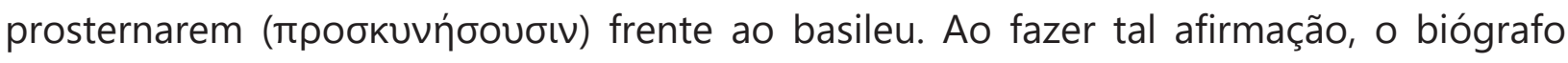
volta a insistir na relação contígua entre os trajes e o exercício do poder. Plutarco afiança tanto o sucesso da empresa de Alexandre - ao se prosternarem, bárbaros e escravos parecem totalmente rendidos ao basileu, satisfazendo sua intenção primeira ao assumir a vestimenta oriental - quanto o comportamento servil atribuído ao Outro fitado pelo discurso de alteridade. Seja seduzido pelo cinturão persa e pela túnica branca, seja atemorizado diante do brandir do açoite medo, o bárbaro enunciado por Plutarco não tem pudores em desvelar sua subserviência ao poder de Alexandre.

\section{Os símiles de Dario e Alexandre}

Além da primeira menção à barbarização de Alexandre e da áspera discussão entre o conquistador e Clito, Plutarco reserva mais uma passagem à discussão sobre os trajes persas. Mantendo o padrão de sua narrativa, o episódio também servirá de molde para enquadrar os comentários plutarquianos a respeito do exercício do poder. 
Às vésperas da Batalha de Gaugamela (331 a.C.), Alexandre ouviu que seus soldados se dividiram em dois grupos e começaram a se digladiar, como que tentando conter a ansiedade diante do iminente combate com os persas. Ao invés de desbaratar a confusão, o macedônio mandou que os chefes dos dois grupos se enfrentassem em um duelo ( $\mu$ ovo $\mu \alpha \chi \eta \hat{\sigma} \sigma \alpha \mathrm{l})$, adotando os nomes dele próprio e de Dario. Alexandre se encarregou de armar seu dublê, ao passo que Filotas o fez com o simulacro do Grande Rei. Ao final de estrênuo embate, o soldado que representava Alexandre, coincidentemente, saiu vitorioso. Como prêmio, recebeu, além de doze aldeias, o direito de usar a vestimenta

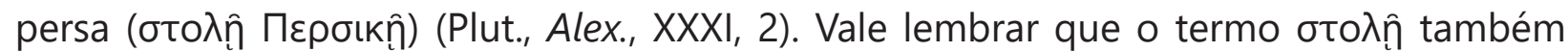
aparece sob a pena de Plutarco (Alex., XLV, 1) para a se referir ao traje bárbaro adotado

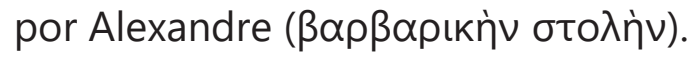

O pitoresco episódio releva outra das facetas assumidas pela indumentária persa no enredo da Vida de Alexandre: um bálsamo destinado àquele que conquistou todos os territórios que conheceu, símbolo inconteste de vitória. Signo, portanto,

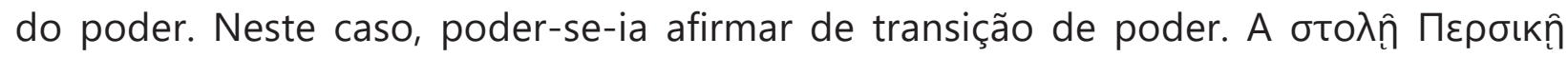
que, por dois séculos, trajou os persas como soberanos da Ásia haverá de passar às mãos de Alexandre. Haverá de ser a perfeita representação da passagem da soberania aquemênida à hegemonia macedônia. Reforça esta hipótese a sugestão de Plutarco (Alex., XXXI, 2) que mesmo aqueles que assistiram ao combate entre os símiles de Dario e Alexandre viram-no como uma espécie de prévia, de presságio, de augúrio (oíwvஸ̣) daquilo que ocorreria em Gaugamela.

Três, até aqui, foram as menções de Plutarco aos trajes estrangeiros na Vida de Alexandre, todas envolvendo imbricações, ao menos tácitas, com os fundamentos do exercício do poder. Na primeira das referências, o biógrafo menciona a vestimenta bárbara como artifício de Alexandre para cativar os habitantes locais; ao passo que, na segunda, a discussão do conquistador com Clito tem a intenção de mostrar como o desejo do basileu

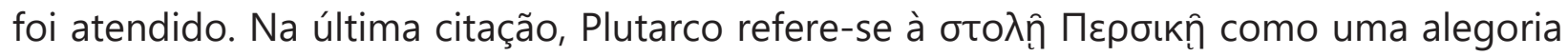
da passagem do domínio persa à hegemonia macedônia. Isto posto, cabe averiguar a existência, no texto plutarquiano, de motivações para a inclinação do basileu às vestes estrangeiras, aspecto que será analisado no último item desta demonstração.

\section{Olímpia, semente do mal, demônio familiar}

Os primeiros passos da Vida de Alexandre são dedicados à filiação e à infância de Alexandre, aspectos pelos quais todas as demais narrativas da tradição textual passam ao largo - ainda que os dois primeiros livros de Quinto Cúrcio, perdidos, talvez dissertassem 
sobre o tema. Além de pontuar que o conquistador descenderia de Hércules, da parte de Filipe, e de Éaco, por parte materna, Plutarco tem a preocupação de nomear todos os tutores responsáveis pela educação do macedônio. Com o autor de Queroneia, aprendese que os preceptores do jovem príncipe foram Leônidas, um parente de Olímpia, Lisímaco, indivíduo oriundo da Acarnânia e que se auto intitulava Fênix, em alusão ao mestre de Aquiles, além de Aristóteles, que dispensa apresentações (Plut., Alex., V, 5).

Ao tratar da relação entre os pais de Alexandre, Plutarco confirma que eles se conheceram em um rito de iniciação na Samotrácia, quando se apaixonaram e foram unidos por intermédio de Aribas, irmão da noiva (Plut., Alex., II, 1). A partir daqui, Plutarco começa a dissertar sobre Olímpia, muitas vezes maldizendo-a e aludindo às suas possíveis origens bárbaras.

A Vida de Alexandre propõe que Olímpia se deitava na companhia de cobras, assustando até o destemido Filipe. O monarca inclusive deixou de dormir com sua consorte por medo dos ofídios ou receio de ser vítima de suas práticas mágicas (Plut., Alex., II, 4). Plutarco segue contundente: afirma que todas as mulheres do Épiro eram

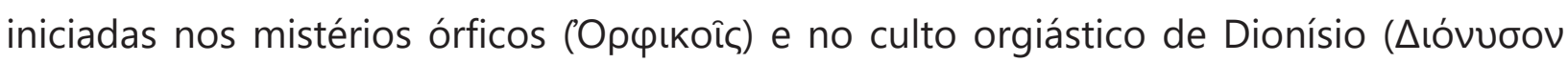

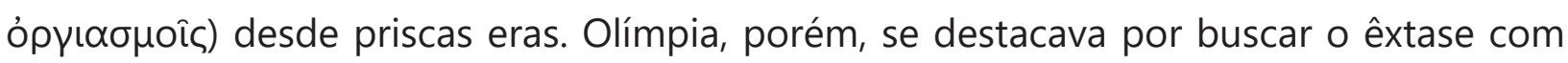
afinco barbaresco ( $\beta \alpha \rho \beta \alpha \rho$ ı́óc), cercando-se de inúmeras serpentes, que, não raro, escapavam de seu controle e causavam verdadeiro terror (Plut., Alex., II, 5-6).

Plutarco carrega nas tintas ao tratar da mãe de Alexandre, caracterizando-a como criatura traiçoeira como as cobras, suas fiéis companheiras. Chama a atenção o fato de o beócio dizer que Olímpia era possuída por furor barbaresco em sua busca pelos êxtases de Orfeu e Dionísio, donde é possível depreender-se que Olímpia pode ser responsável pelos traços bárbaros da complexa personalidade de Alexandre. Ainda que a princesa do Épiro não possa ser tachada como bárbara, em sentido estrito ou largo, seu papel na aproximação de Alexandre dos costumes persas não é menos negligenciável: por ter passado a infância ao lado do futuro rei e pela importância dada por Plutarco a esta etapa da vida, Olímpia pode ter sido uma espécie de porta de entrada, faísca que gerou o incendiário desejo do basileu de assumir aspectos da coroa persa em idade adulta.

Tais impressões são reforçadas em outras passagens da Vida de Alexandre. A certa altura (Plut., Alex., IX, 3-4), Plutarco discorre a respeito dos muitos casos furtivos de Filipe, cujas consequências eram graves devido ao temperamento de Olímpia, ciumento

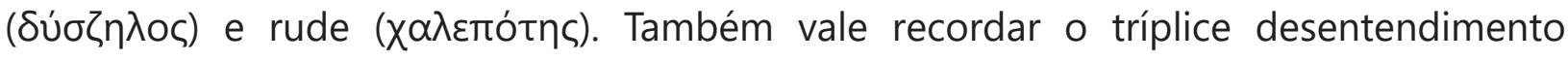
entre Alexandre, Felipe e Átalo, durante o casamento do rei macedônio com Cleópatra, sobrinha de Átalo (Plut., Alex., IX, 4-5). Durante a ríspida discussão, este último insinua que Alexandre seria um bastardo (vó $\theta$ ol), ao mesmo tempo que roga para que Filipe 
e Cleópatra tenham um sucessor legítimo. Neste trecho, fica nítido como a raiz do bastardamento de Alexandre é Olímpia.

Ao final de seu texto, Plutarco garante que Olímpia promoveu uma carnificina após a morte de Alexandre. Acreditando que o filho havia sido envenenado, mandou dar cabo de lolaos (Plut., Alex., LXXVII, 1). Mesmo o meio irmão de Alexandre, Arrideu, foi vítima da perversidade da princesa do Épiro. O autor de Queroneia revela que sua debilidade mental não era uma vicissitude da fortuna ou da doença: era fruto da crueldade de Olímpia, que administrava drogas ( $\varphi \alpha \rho \mu \alpha ́$ koıৎ) a Arrideu desde sua infância, fazendo ruir sua razão (Plut., Alex., LXXVII, 5).

Todavia, a passagem mais intrigante ocorre após a Batalha do Rio Grânico, em 334 a.C. Em seguida à vitória greco-macedônia, Alexandre recolhe o butim para enviar a seus íntimos. Após brindar os atenienses com os escudos dos vencidos, o conquistador

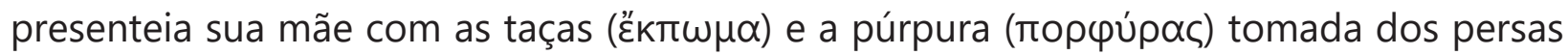

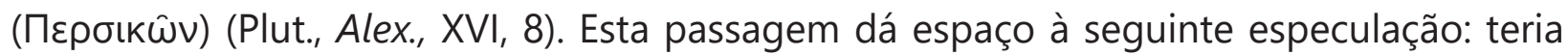
Alexandre enviado os presentes à Olímpia por um suposto apreço dela pelos artefatos persas? Se sim, em que medida ela teria influenciado Alexandre neste gosto, que ficaria mais latente com a conquista da Ásia?

Ao se recordar da importância dada por Plutarco à meninice do macedônio, o raciocínio acima ganha força. Para nos atermos apenas a dois episódios - decerto de cunho anedótico, mas fundamentais para compreender o peso da infância no texto plutarquiano -, vale rememorar a chegada de uma comitiva persa à Macedônia durante a ausência de Filipe. Na falta de seu pai, é Alexandre o responsável por recebê-la. Plutarco expõe que o cortejo do Grande Rei ficou boquiaberto ao ver o jovem interpelando-o

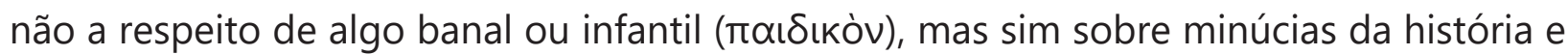
geografia persas, em clara demonstração de astúcia (Plut., Alex., IV, 1). Alexandre parece elaborar as perguntas a propósito das conquistas que iria empregar, quase como se as engendrasse desde seu nascimento.

Outra cena lapidar ocorre quando Alexandre consegue domar o arredio cavalo Bucéfalo, surpreendendo Filipe (Plut., Alex., VI, 1). Pouco antes, seu pai havia ponderado que o animal era por demais arisco para ser usado em batalhas. A forma como o jovem macedônio adestra o equino aparece quase como um comentário à alegoria da caverna platônica: o jovem descobre que Bucéfalo temia sua própria sombra e, lentamente, o faz erguer a cabeça em direção ao sol, afastando seus medos. Mesmo com sua fisionomia anedótica, dois aspectos importantes são delineados: a influência platônica no beócio e a forma como Alexandre faz menção ao topos do rei filósofo (WHITMARSH, 2002, p. 181). 
Diante do corpo de referências reunido, parece ser difícil diminuir o peso da infância de Alexandre em suas atitudes futuras. Esta ponderação acaba por desvelar a última associação entre os trajes estrangeiros e o poder no relato plutarquiano; se antes o ponto era relacionar a vestimenta bárbara ao poderio exercido pelos (e sobre os) persas, agora a questão é compreender o poder de Olímpia sobre Alexandre, entender a ascendência daquela sobre seu filho e sua busca pelo êxtase dionisíaco e órfico de maneira barbaresca, que parecia nutrir gosto pela púrpura dos persas.

Se, como visto, não são poucos os encômios dirigidos pelo beócio ao imberbe Alexandre, e tampouco são desprezíveis seus comentários negativos a respeito de Olímpia, Plutarco bem poderia ter usado outra vez da metáfora dos trajes estrangeiros para fazer

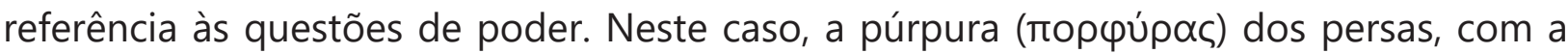
qual Olímpia foi presenteada, constituiria um pretexto para Plutarco insinuar sobre o poder nefasto que uma companhia indesejada pode exercer durante a infância - mesmo como toda a sorte de tutores ilustres que Alexandre tinha à disposição, sua educação e comedimento parecerem ter erodido frente à corrupção barbaresca exalada por Olímpia. A propósito, uma vez que Plutarco ganhava a vida proferindo palestras moralizantes aos membros da aristocracia romana, a preocupação do beócio com os pormenores da educação e da infância bem poderia representar uma defesa de causa própria.

Uma última consideração faz-se válida antes de encerrar o artigo. Admitindo-se que Plutarco tenha escrito a Vida de Alexandre em algum momento após o principado de Trajano, aspecto de valia são as campanhas do imperador espanhol contra os dácios (105/106) e partas (113). É sabido que a relação entre persas e partas era quase de associação unívoca, ao menos no entender greco-romano. Rufus Fears (1974), por exemplo, constatou que os romanos usavam os termos parthi (parta) e persae (persa) como sinônimos. Sendo assim, seria possível que Plutarco descrevesse os persas de sua Vida de Alexandre à luz dos partas combatidos por Trajano?

A especulação ganha campo quando se recorre à História de Roma, de Dion Cássio, para ilustrar as empreitadas de Trajano. Duas cenas são notáveis, sendo a primeira a rendição do líder do dácios, Decébalo (87-106) diante de imperador. Narra Dion Cássio (Historiae romanae, LXVIII, 9, 6-7; LXVIII, 18, 2) que o comandante dácio

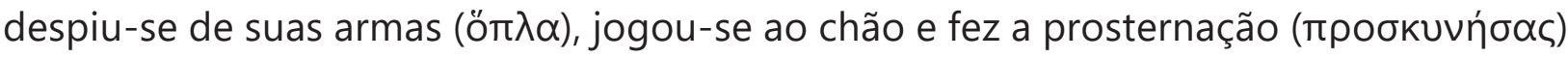
frente ao césar. Noutra passagem, Dion Cássio (Hist. Rom., LXVIII, 18, 2) afirma que, ao chegar ao território parta, diversos príncipes e sátrapas vieram em direção a Trajano, oferecendo-Ihe regalos. Entre os presentes, havia um cavalo a quem foi ensinado fazer

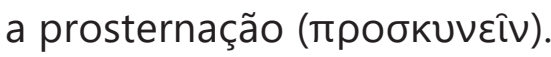


A despeito da exiguidade dos relatos e da análise superficial dada a eles neste texto, vê-se que a construção dos persas em Plutarco e dos dácios e partas em Dion Cássio possuem pontos em comum, em especial a fraqueza associada ao Outro. Como se fossem sucessores do Grande Rei, ambos se rendem ao poderio romano, jogando-se aos pés de seu vencedor em clemência - ainda que Decébalo ao menos tenha tido a dignidade de cometer o suicídio, em cena retratada inclusive na coluna de Trajano. Mais do que isso, dácios e partas fazem uso da prosternação, ritual tomado pelos gregos como a marca distinta da alteridade persa (GARCÍA SÁNCHEZ, 2013). Pondo estas informações em linha de conta, seria possível conjecturar que Plutarco colocaria as campanhas de Alexandre contra os persas quase como se fossem uma prévia das expedições de Trajano?

Para tentar responder à indagação, vale a pena tomar outra vez as páginas de Dion Cássio (Hist. Rom., LXVIII, 7, 4). O historiador relata que Trajano tinha certa queda por vinho e jovens imberbes, embora isto não o tivesse levado a cometer atos espúrios

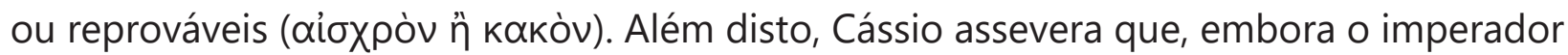
espanhol tivesse tomado tanto vinho (oîvou) quanto desejasse, ele, ainda assim, permaneceu sóbrio ( $v n \dot{\varphi} \omega \nu)$. Se Plutarco nutria especial preocupação pelos impulsos daqueles que biografava, seria possível que ele ignorasse um imperador contemporâneo que ostentava a paradoxal pecha de beberrão sóbrio?

É notório que o beócio mantinha relações muito próximas com as cepas da aristocracia imperial - basta lembrar seu sacerdócio no templo de Delfos, que, decerto, não seria entregue a um incauto. Ademais, foi graças à admiração de Trajano que Alexandre voltou a ser tomado em alta conta entre a camada senatorial (WITHMARSH, 2002). Algumas citações são indispensáveis para aludir a tal admiração, como a carta enviada ao Senado pelo César, na qual ele lamentava sua idade avançada, que o impedia de seguir pela trilha de Alexandre, e a citação, novamente de Cássio (Hist. Rom., LXVIII, $26,1)$, de que Trajano guardava certa jactância por ter marchado até Gaugamela, local da última e decisiva vitória de Alexandre sobre Dario (QUARANTA, 2012, p. 7).

Munido do apreço de Trajano por Alexandre, suas campanhas contra dácios e partas, e, do fato, de Plutarco ter gozado dos favores da aristocracia romana, resta a última indagação: seria possível que o beócio estivesse tentando justificar - ou mesmo elogiar - as ações de Trajano por meio de sua narrativa de Alexandre? Plutarco, por fim, aparece descrito como um orador e escritor que se valeu de benesses das elevadas camadas do Império para a escalada de sua fama. Teria ele conseguido tais favores beneficiando-se de obras que mostrassem os membros destas mesmas camadas com atributos semelhantes àqueles de figuras respeitáveis do passado greco-romano? Teria o beócio tomado a pena munido do desejo de torná-la instrumento de ascensão política? 
Ainda que o campo especulativo norteie os parágrafos acima, parece válido mencioná-lo à medida que se problematiza o extenso corpus plutarquiano, complexo e fascinante por si só. Estudá-lo de forma cada vez mais questionadora parece ser o caminho para que a pequenina Queroneia não seja lembrada apenas por ser o palco da vitória de Filipe sobre a coalizão grega, mas, sobretudo, por ser o berço de um dos mais profícuos e louvados escritores da Antiguidade.

\section{Considerações finais}

Diante do que foi apresentado, a adoção de trajes estrangeiros por Alexandre Magno apresenta diversas nuances e complexidades na narrativa plutarquiana, ainda que todas elas tenham a questão do exercício do poder como pano de fundo. Partindo deste pressuposto, o principal objetivo deste texto foi enfatizar as possíveis resultantes ligadas às relações de poder e à narrativa de alteridade e construção do Outro persa oferecidas pelos excertos de Plutarco. Desta forma, foi possível notar que, talvez mais do que críticas a Alexandre, as passagens analisadas acabam por corroborar chavões da alteridade grega sobre a dinastia aquemênida, cristalizados desde as Guerras Greco-Pérsicas. Por fim, rápida menção foi feita à possível influência que o cenário romano pode ter estabelecido sobre a Vida de Alexandre, de maneira a aludir às passagens envolvendo a biografia de um dos mais afamados conquistadores da Antiguidade.

\section{Referências}

\section{Documentação textual}

ARRIAN. Anabasis Alexandri. Leipzig: Teubneri, 1907.

DIODORUS SICULUS. Bibliotheca Historica. Leipzig: Teubneri, 1888-1890. v. 1-2.

EURIPIDES. Andromaca. Translated by David Kovacs. Cambridge: Harvard University Press, 1994.

HERODOTUS. Historiae. Translated by A. D. Godley. Cambridge: Harvard University Press, 1920.

PLUTARCO. Lives Demosthenes and Cicero, Alexander and Caesar. Translated by Bernadotte Perrin. Cambridge: Harvard University Press, 2004.

PLUTARCO. Vida de Alejandro Magno. In: PLUTARCO; DIODORO síCULO. Alejandro Magno.

Traducctión de Antonio Guzmán Guerra. Madrid: Akal, 1986.

PLUTARCO. Vie d'Alexandre. Traduit par Émile Chambry. Paris: Les Belle Lettres, 1986. 
QUINTO CÚRCIO. Historia de Alejandro Magno. Madrid: Gredos, 1986.

STRABO. Geographica. Leipzig: Teubner, 1877.

XENOPHON. Opera omnia. Oxford: Clarendon Press, 1910.

\section{Obras de referência}

HOUAISS, A. Dicionário Houaiss da língua portuguesa. Rio de Janeiro: Objetiva, 2001.

LIDDELL, H.; SCOTT, R. A Greek-English lexicon. Oxford: Oxford Univesity Press, 1996.

\section{Obras de apoio}

BICHLER, R.; ROLLINGER, R. The image of Persia and Persians in Greek literature. Encyclopaedia Iranica, fasc. 3, v. 11, p. 326-329, 2002.

BOWMAN, A.; WOOLF, G. Cultura escrita e poder no Mundo Antigo. In: BOWMAN, A.; WOOLF, G. (Org.). Cultura escrita e poder no Mundo Antigo. São Paulo: Ática, 1998, p. 5-23.

BRIANT, P. From Cyrus to Alexandre: a history of the Persian Empire. Indiana: Enseinbrauns Press, 2002.

COHEN, B. The non-Greek in the Greek art. In: SMITH, T.; PLANTZOS, D. (Ed.). A Companion to Greek art. Wiley: Blackwell, 2012, p. 456-479.

EDMUNDS, L. Ancient Roman and modern American food: a comparative sketch of two semiological systems. Comparative Civilizations Review, n. 5, p. 52-69, 1980.

FEARS. J. Parthi in Q. Curtius Rufus. Hermes, n. 102, p. 623-625, 1974.

GARCÍA-SÁNCHEZ, M. El discurso sobre el bárbaro: Aqueménidas, Arsácidas y Sasánidas en las fuentes grecorromanas. In: FORNIS, C. (Ed.). Los discursos del poder: el poder de los discursos en la Antigüedad Clássica. Zaragoza: Portico, 2013, p. 55-72.

GARCÍA-SÁNCHEZ, M. El Gran Rey de Persia: formas de representación de la alteridad persa en el imaginario griego. Barcelona: Ed. Universidad Barcelona, 2009.

GARCÍA-SÁNCHEZ, M. Los bárbaros y el bárbaro: identidad griega y alteridad persa. Faventia, n. 27, p. 33-49, 2007.

GARCÍA-SANCHÉZ, M.; ALBALADEJO-VIVERO, M. Diademas, tiaras y coronas de la antígua Persia: formas de representación y de adopción en el mundo clásico. In: ALFARO, C.; ORTIZ, J.; ANTÓN, M. (Ed.). Tiarae, diadems and headdresses in the ancient mediterranean cultures. Valencia: Sema, 2014, p. 79-94.

GOLDMAN, B. Darius III, the Alexander Mosaic and the Tiara Ortho. Mesopotamia, n. 28, p. 51-69, 1993. 
GRUEN, E. Rethinking the other in Antiquity. Princeton: Princeton University Press, 2011.

HALL, E. Inventing the barbarian: Greek self-definition through tragedy. Oxford: Oxford University Press, 1989.

HALL, J. Ethnic identity in Greek Antiquity. Cambridge: Cambridge University Press, 1997. HARTOG, F. Memória de Ulisses: narrativas sobre a fronteira na Grécia Antiga. Belo Horizonte: Ed. UFMG, 2004.

HARTOG, F. O espelho de Heródoto: ensaio sobre a representação do outro. Belo Horizonte: Editora UFMG, 1999.

JONES, C. Towards a chronology of Plutarch's works. The Journal of Roman Studies, v. 56, p. 61-74, 1966.

MARTIN, H. Plutarch and his times. The American Journal of Philology, v. 90, n. 3, p. 368$371,1969$.

QUARANTA, E. Corpus Magni Alexandri... Veneratus est. Nures, v. 20, p. 1-9, 2012.

ROACH-HIGGINS, M.; EICHER, I. Dress and identity. Clothing and Textile Research Journal, v. 10, n. 4, p. 1-8, 1992.

ROAF, M. Texts about the sculptures and sculptors at Persepolis. Iran, v. 21, p. 1-164, 1983.

SILVA, M. Plutarco e a tradição cultural grega no Império. História em Reflexão, v. 4, p 1-14, 2008.

SILVA, M. Plutarco historiador: análise das biografias espartanas. São Paulo: Ed. Universidade de São Paulo, 2006.

STADTER, P. Plutarch and Rome. In: BECK, M. (Ed.). A Companion to Plutarch. Wiley: Blackwell, 2014, p. 13-31.

STARR, R. The circulation of literary texts in the Roman world. The Classical Quarterly, v. 37, p. 213-223, 1987.

TODOROV, T. A conquista da América: a questão do outro. São Paulo: Martins Fontes, 2003.

VLASSOPOULOS, K. Greeks and barbarians. Cambridge: Cambridge University Press, 2013. WARDMAN, A. Plutarch and Alexander. The Classical Quarterly, v. 5, p. 96-107, 1955.

WHITMARSH, T. Alexander's hellenism and Plutarch's textualism. The Classical Quarterly, v. 52, n. 1, p. 174-192, 2002. 